\title{
Polymorphisms rs699 and rs4762 of the Angiotensinogen Gene and Progression of Carotid Atherosclerosis in Patients with Type 2 Diabetes Mellitus
}

\author{
Sebastjan Merlo ${ }^{1}$, Jovana Nikolajević Starcević ${ }^{2}$, Sara Mankoč ${ }^{2}$, Marija Santl Letonja ${ }^{3}$, Andreja Cokan Vujkovac $^{4}$, Peter Kruzliak ${ }^{5}$, Daniel Petrovič ${ }^{\star}$ \\ ${ }^{1}$ Institute of Oncology, Ljubljana, Slovenia \\ 2Institute of Histology and Embryology, University of Ljubljana, Slovenia \\ ${ }^{3}$ General Hospital Rakičan, Murska Sobota, Slovenia \\ ${ }^{4}$ General Hospital Slovenj Gradec, Slovenia
}

${ }^{5}$ Department of Cardiovascular Diseases, International Clinical Research Center, St Anne's University Hospital and Masaryk University, Pekarska 53, 65691 Brno, Czech Republic

*Corresponding author: Daniel Petrovič, MD, PhD, Faculty of Medicine, Institute of Histology and Embryology, Ljubljana, University Ljubljana, Korytkova 2, 1105 Ljubljana, Slovenia, Tel +386 1543 7367; Fax + 3861543 7361; E-mail: daniel.petrovic@mf.uni-lj.si

Rec date: February 23, 2016; Acc date: May 07, 2016; Pub date: May 16, 2016

Copyright: (c) 2016 Merlo S, et al. This is an open-access article distributed under the terms of the Creative Commons Attribution License, which permits unrestricted use, distribution, and reproduction in any medium, provided the original author and source are credited.

\begin{abstract}
Background: The aim of the study was to investigate the association between two polymorphisms of the angiotensinogen (AGT) gene ( $r$ 699 and rs4762) and subclinical markers of carotid atherosclerosis in subjects with type 2 diabetes mellitus (T2DM).

Patients and methods: In this cross-sectional study 599 subjects with T2DM and 200 subjects without T2DM (control group) were enrolled. The CIMT and plaque characteristics (presence/absence and plaque thickness) on both the near and the far walls in the common carotid artery, bulb and internal carotid arteries, bilaterally were assessed ultrasonographically. After several years ( $3.8 \pm 0.5$ years), patients were re-assessed and changes in subclinical markers of carotid atherosclerosis were calculated. Polymorphisms rs699 and rs4762 of the AGT gene were genotyped by using allele-specific PCR (KASPar) assay.
\end{abstract}

Results: The highest increase in carotid plaque thickness was observed in homozygote carriers of the A allele, even after adjustment for confounding variables. Polymorphism rs699 did not affect the progression of CIMT in the increase of number of segments with plaques.

Conclusions: In the study we have found that the rs699 of the AGT gene is a potential genetic marker of carotid atherosclerosis progression (expressed as increase in carotid plaque thickness) in Slovenian patients with T2DM. It did not affect other ultrasonographic markers of carotid atherosclerosis progression. Polypmorphism rs4762 was not associated with carotid atherosclerosis progression in Slovenian patients with T2DM.

Keywords: Diabetes mellitus; Carotid aterosclerosis; Intima-media thickness; Angiotensinogen; rs699 polymorphism

\section{Introduction}

Cardiovascular and cerebrovascular diseases are leading causes of mortality in patients with diabetes mellitus [1,2]. Beside diabetes mellitus, some of the traditional risk factors, such as hypertension, hypercholesterolaemia, smoking and positive family history, contribute as well to the high prevalence of cardiovascular disease in subjects with diabetes mellitus [2].

Ultrasound examination of carotid arteries enables visualization of different aspects of atherosclerosis. Beside carotid intima-media thickness (CIMT), which is the most studied non-invasive phenotype of carotid atherosclerosis, we can also measure plaque thickness, total plaque area, plaque volume, determine type of plaques, and degree of stenosis [3]. CIMT is a good marker of early atherosclerosis and its progression [4]. It correlates well with cardiovascular risk factors and future cardiovascular events $[5,6]$.
Some polymorphisms of the genes of the RAAS system have been so far associated with atherosclerotic cardiovascular disease $[7,8]$. Moreover, it has been reported that the renin angiotensin aldosterone system (RAAS) might affect CIMT and carotid atherosclerosis [9-13]; however, results are highly inconsistent.

The angiotensinogen (AGT) gene, an important gene of the RAAS system, is located in the long arm of chromosome 1 (gene locus 1q42q43). The most studied AGT polymorphism, the rs699 (M235T) polymorphism, was reported to correlate with plasma AGT concentrations, whereas the highest levels of AGT are seen in the TT homozygotes [14-16]. There is still a limited number of studies focused on the association between the rs699 (M235T) and other AGT gene polymorphisms and markers of carotid atherosclerosis in the general population, and only one study in subjects with T2DM. Available data did not provide evidence of an association between the polymorphism of the genes in the RAS and either CIMT or the presence of carotid plaques in the general population, whereas only one study was performed in subjects with T2DM [8,9,17-20]. 
Citation: Merlo S, Starcevic JN, Mankoc S, Letonja MS, Vujkovac AC, et al. (2016) Polymorphisms rs699 and rs4762 of the Angiotensinogen Gene and Progression of Carotid Atherosclerosis in Patients with Type 2 Diabetes Mellitus. J Diabetic Complications Med 1: 107. doi: $10.4172 / \mathrm{jdcm} .1000107$

Page 2 of 5

The aim of the study was to investigate the association between two polymorphisms of the angiotensinogen (AGT) gene (rs699 and rs4762) and subclinical markers of carotid atherosclerosis in subjects with T2DM.

\section{Methods}

\section{Patients}

In this prospective study 599 subjects with T2DM and 200 subjects without T2DM (control group) were enrolled.

Among patients with T2DM 399 were on statin therapy: 58.6\% (234) received atorvastatin $20 \mathrm{mg}$ per day, $22.5 \%(90)$ received rosuvastatin $10 \mathrm{mg}$ per day and $18.9 \%$ (75) received simvastatin $40 \mathrm{mg}$ per day, while 196 were without hypolipemic therapy. They were selected among patients admitted to the diabetes outpatient departments of two general hospitals (Murska Sobota and Slovenj Gradec), and from cardiology outpatient department Medicor, Ljubljana, as described previously [21].

\section{Ultrasonographic analysis}

A high resolution B mode ultrasound analysis was performed using a portable ultrasound system, Toshiba Aplio SSA-700 (Toshiba
Medical. Sys-tem Corp., Tokyo, Japan). All examinations were performed by two radiologists, blinded to the participants' diabetes status, as described previously [22]. The CIMT was measured at 3 sites along the $10 \mathrm{~mm}$ long segment of the far wall of the CCA free of plaques, in agreement with the carotid intima-media thickness consensus, as described previously [21,22]. The interobserver reliability for CIMT measurements was found to be substantial $(\kappa=0.74, \mathrm{p}<$ 0.001) [22]. Moreover, plaques and type of plaques according to echogenic/echolucent characteristics were idefined and plaque thickness was measured in the common carotid artery, bulb and internal carotid artery, bilaterally, as described previously [22,23]. The interobserver reliability for carotid plaque characterization was found to be substantial $(\kappa=0.64, \mathrm{p}<0.001)$. After several years $(3.8 \pm 0.5$ years), patients were re-assessed and subclinical markers of carotid atherosclerosis were checked again.

\section{Biochemical analyses}

Blood samples for biochemical analyses (total cholesterol, triglyceride levels, high-density lipoprotein (HDL), low-density lipoprotein (LDL) cholesterol level, fasting blood glucose and glycated haemoglobin ( $\mathrm{HbAlc}$ ), and hsCRP) were collected, and all the biochemical analyses were determined in the hospital's accredited lab, as described previously [24].

\begin{tabular}{|c|c|c|c|}
\hline & Subjects with T2DM & Control group & \\
\hline & $n=595$ & $\mathrm{n}=\mathbf{2 0 0}$ & $\mathbf{p}$ \\
\hline Age (years) & $61.38 \pm 9.65$ & $60.07 \pm 9.18$ & 0.07 \\
\hline Male sex (\%) & $338(56.8)$ & $92(46.0)$ & 0.008 \\
\hline Diabetes duration (years) & $11.25 \pm 7.88$ & - & - \\
\hline Cigarette smoking (\%) & $53(8.91)$ & $34(17.0)$ & 0.002 \\
\hline Waist circumference (cm) & $108.65 \pm 12.88$ & $93.31 \pm 13.18$ & $<0.001$ \\
\hline BMI $\left(\mathbf{k g} / \mathbf{m}^{2}\right)$ & $30.96 \pm 4.74$ & $27.90 \pm 4.42$ & 0.16 \\
\hline SBP $(\mathrm{mm} \mathrm{Hg})$ & $146.98 \pm 19.98$ & $143.3 \pm 16.6$ & 0.86 \\
\hline $\mathrm{DBP}(\mathrm{mm} \mathrm{Hg})$ & $85.75 \pm 11.62$ & $84.7 \pm 11.6$ & 0.19 \\
\hline Fasting glucose (mmol/l) & $8.04 \pm 2.57$ & $5.27 \pm 0.87$ & $<0.001$ \\
\hline HbA1c (\%) & $7.89 \pm 3.56$ & $4.79 \pm 0.29$ & $<0.001$ \\
\hline Total cholesterol (mmol/l) & $4.70 \pm 1.19$ & $5.36 \pm 1.08$ & $<0.001$ \\
\hline HDL cholesterol (mmol/l) & $1.19 \pm 0.35$ & $1.43 \pm 0.37$ & $<0.001$ \\
\hline LDL cholesterol (mmol/l) & $2.63 \pm 0.94$ & $3.24 \pm 0.98$ & $<0.001$ \\
\hline Triglycerides (mmol/l) & $1.9(1.2-2.7)$ & $1.3(0.9-1.9)$ & $<0.001$ \\
\hline hs - CRP (mg/l) & $2.2(1.0-4.3)$ & $1.3(0.8-2.7)$ & $<0.001$ \\
\hline
\end{tabular}

Table 1: Demographic and laboratory characteristics of subjects with T2DM and subject without T2DM (control group). 
Citation: Merlo S, Starcevic JN, Mankoc S, Letonja MS, Vujkovac AC, et al. (2016) Polymorphisms rs699 and rs4762 of the Angiotensinogen Gene and Progression of Carotid Atherosclerosis in Patients with Type 2 Diabetes Mellitus. J Diabetic Complications Med 1: 107. doi: $10.4172 / \mathrm{jdcm} .1000107$

Page 3 of 5

\section{Genotyping}

The genomic DNA was extracted from $100 \mu \mathrm{L}$ of whole blood using a FlexiGene DNA isolation kit, in accordance with the recommended protocol (Qiagene GmbH, Hilden, Germany). The AGT rs699 and rs4762 polymorphisms were genotyped by novel fluorescence-based competitive allele-specific PCR (KASPar) assay (KBioscience Ltd). Details of the method used can be found at http:// www.kbioscience.co.uk/.

\section{Statistical analysis}

Continuous variables were expressed as means \pm standard deviations, and as median (interquartile range) when asymmetrically distributed was examined by the Kolmogorov-Smirnov test was used to examine the normality of the continuous variables. Continuous clinical data were compared using an unpaired Student's t test or analysis of variance (ANOVA) when normally distributed, and the MannWhitney U-test or the Kruskal-Wallis H-test when asymmetrically distributed. The Pearson X2 test was used to compare discrete variables and to test whether the genotypes distribution is in Hardy-Weinberg equilibrium. Moreover, pairwise linkage disequilibrium (LD; D' and $\mathrm{r}^{2}$ ) between SNPs were calculated with Haploview software. rs699 and rs4762 were in complete $\mathrm{LD}\left(\mathrm{D}^{\prime}=1 ; \mathrm{r}^{2}=0.21\right)$.

Pearson's correlation was performed to examine the association between independent variables.

A multivariate linear regression analysis was performed to determine the association of the AGT rs699 and rs4762 polymorphisms with the CIMT. To determine the association of the AGT rs699 and rs4762 polymorphisms with the presence of atherosclerotic plaques on the carotid arteries, a multivariate logistic regression analysis was performed. A two-tailed $\mathrm{P}$ value of less than 0.05 was considered statistically significant. A statistical analysis was performed using the SPSS program for Windows version 22 (SPSS Inc., Chicago, IL).

\section{Results}

The baseline clinical and biochemical characteristics of the study participants are shown in Table 1. There were no statistically significant differences in age, BMI and systolic and diastolic blood pressure between patients with T2DM and subjects without T2DM. Patients with T2DM had greater waist circumference, higher fasting glucose and HbAlc levels than the controls. Smoking prevalence was lower in patients with T2DM than in the control group. A comparison of the lipid parameters showed lower total, HDL, LDL cholesterol levels and a higher triglyceride level in patients with T2DM than in controls. Plasma levels of (hs-CRP was statistically significantly higher in patients with T2DM than in controls.

The AGT rs699 and rs4762 genotypes distribution and allele frequencies among the study subjects are shown in Table 2. The genotype distributions in both patients with T2DM and controls were compatible with Hardy-Weinberg expectations (rs699: T2DM: $\chi^{2}=$ 0.09; $\mathrm{p}=0.77$; healthy controls $\chi^{2}=1.00 ; \mathrm{p}=0.32$; rs4762: T2DM: $\chi^{2}=$ $0.005 ; \mathrm{p}=0.94$; healthy controls $\chi^{2}=2.98 ; \mathrm{p}=0.08$ ). No statistically significant difference in the AGT rs699 and rs4762 genotypes distribution and allele frequencies was observed between patients with DM2 and the control group.

\begin{tabular}{|c|c|c|c|}
\hline rs699 & Subjects with T2DM n=595 & Control group $n=200$ & $\mathbf{p}$ \\
\hline GG & $123(20.7)$ & 37 (18.5) & \multirow{3}{*}{0.74} \\
\hline GA & $299(50.3)$ & $106(53.0)$ & \\
\hline AA & $173(29.0)$ & $57(28.5)$ & \\
\hline \multicolumn{4}{|c|}{ Allele frequencies } \\
\hline G & $545(45.8)$ & $180(45.0)$ & \multirow{2}{*}{0.78} \\
\hline A & $645(54.2)$ & $220(55.0)$ & \\
\hline \multicolumn{4}{|c|}{ rs4762 } \\
\hline GG & $425(71.4)$ & $146(73.0)$ & \multirow{3}{*}{0.34} \\
\hline GA & $156(26.2)$ & $46(23.0)$ & \\
\hline AA & $14(2.4)$ & $8(4.0)$ & \\
\hline \multicolumn{4}{|c|}{ Allele frequencies } \\
\hline G & $1006(84.5)$ & $338(84.5)$ & \multirow{2}{*}{1} \\
\hline A & $184(15.5)$ & $62(15.5)$ & \\
\hline
\end{tabular}

Table 2: Genotype distribution of rs699 AGT and rs4762 in subjects with T2DM and control group.

Neither rs699 nor rs4762 had statistically significant impact on the CIMT at baseline (rs699: GG genotype vs. GA genotype vs. AA genotype $=980 \pm 195 \mu \mathrm{m}$ vs. $994 \pm 187 \mu \mathrm{m}$ vs. $1006 \pm 196 \mu \mathrm{m}, \mathrm{p}=0.4$; rs4762: GG genotype vs. GA genotype vs. AA genotype $=998 \pm 193$ $\mu \mathrm{m}$ vs. $1002 \pm 187 \mu \mathrm{m}$ vs. $1007 \pm 189 \mu \mathrm{m}, \mathrm{p}=0.6$ )

\begin{tabular}{|l|l|l|l|l|}
\hline rs699 & GG & GA & AA & p \\
\hline Annual increase in CIMT $(\mu \mathrm{m} /$ year) & $12.41(10.52-8.66)$ & $17.14(11.23-24.33)$ & $21.05(20.33-33.65)$ & 0.59 \\
\hline$\Delta$ number of segments with plaques & $2.0(1.0-3.0)$ & $2.3(1.4-3.6)$ & $2.5(1.25-3.0)$ & 0.16 \\
\hline$\Delta$ sum of carotid plaques thickness $(\mathrm{mm})$ & $5.45(2.17-7.30)$ & $6.30(3.40-8.45)$ & $7.30(3.40-10.77)$ & 0.03 \\
\hline$\Delta$-changes in variables in observed time period expressed as percentage of the initial value & & \\
\hline \multicolumn{2}{|l}{ CIMT - Carotid Intima Media Thickness }
\end{tabular}

Table 3: Changes of subclinical markers of carotid atherosclerosis in subjects with T2DM between first examination and control examination with regard to the genotypes of the rs699 polymorphism of the AGT. 
Citation: Merlo S, Starcevic JN, Mankoc S, Letonja MS, Vujkovac AC, et al. (2016) Polymorphisms rs699 and rs4762 of the Angiotensinogen Gene and Progression of Carotid Atherosclerosis in Patients with Type 2 Diabetes Mellitus. J Diabetic Complications Med 1: 107. doi: $10.4172 / \mathrm{jdcm} .1000107$

Page 4 of 5

Comparison of atherosclerosis progression (changes of markers of carotid atherosclerosis after $3.8 \pm 0.5$ years) showed the highest increase in carotid plaque thickness in subjects with T2DM carriers of the AA genotype of the $\mathrm{rs} 699$ ( $\mathrm{p}=0.03$ ). Although we observed the highest annual increase in CIMT and increase in number of sites with plaques in homozygotes for allele $\mathrm{A}$, the differences were not statistically significant (Table 3).
In the present study we observed no statistically significant difference in atherosclerosis progression between carriers of different genotypes of the rs 4762 polymorphism (Table 4 ).

\begin{tabular}{|l|l|l|l|}
\hline rs4762 & GG & GA+AA & p \\
\hline Annual increase in CIMT $(\mu \mathrm{m} /$ year) & $14.29(10.71-21.05)$ & $26.08(15.43-33.65)$ & 0.81 \\
\hline$\Delta$ number of segments with plaques & $2.0(1.5-3.0)$ & $1.0(0.5-2.5)$ & 0.24 \\
\hline$\Delta$ sum of carotid plaques thickness $(\mathrm{mm})$ & $6.10(3.50-7.60)$ & $4.4(2.45-6.90)$ & 0.08 \\
\hline$\Delta$-changes in variables in observed time period expressed as percentage of the initial value & \\
\hline \multicolumn{2}{|l}{} \\
\hline
\end{tabular}

Table 4: Changes of subclinical markers of carotid atherosclerosis in subjects with T2DM between first examination and control examination with regards to the genotypes of the rs 4762 polymorphism of the AGT.

As shown by multivariable linear regression analysis, the association of the AA genotype with highest increase in carotid plaque thickness remained significant even after adjustment for confounding variables (Table 5).

\begin{tabular}{|c|c|c|c|c|c|c|}
\hline \multirow{2}{*}{ rs699 of the AGT gene* } & $\Delta$ CIMT/year & & $\begin{array}{l}\Delta \text { number } \\
\text { segments }\end{array}$ & & $\begin{array}{l}\Delta \text { sum of plaques } \\
\text { thickness }\end{array}$ & \\
\hline & B & $\mathbf{p}$ & $\beta$ & $\mathbf{p}$ & $\beta$ & $\mathbf{P}$ \\
\hline Hypertension (0=no; $1=y e s)$ & 0.082 & 0.87 & 0.124 & 0.82 & 0.264 & 0.56 \\
\hline Systolic blood pressure $(\mathrm{mm} \mathrm{Hg})$ & 0.019 & 0.92 & 0.029 & 0.37 & 0.037 & 0.54 \\
\hline Genotype GA rs699 & 0.145 & 0.22 & 0.09 & 0.57 & 0.159 & 0.62 \\
\hline Genotype AA rs699 & 0.359 & 0.4 & 0.149 & 0.4 & 0.301 & 0.02 \\
\hline \multicolumn{7}{|l|}{ rs4762 of the AGT gene ${ }^{*}$} \\
\hline Hypertension (0=no; $1=y e s)$ & 0.067 & 0.66 & 0.147 & 0.79 & 0.464 & 0.26 \\
\hline Systolic blood pressure $(\mathrm{mm} \mathrm{Hg})$ & 0.078 & 0.62 & 0.035 & 0.28 & 0.046 & 0.31 \\
\hline$G A+A A$ of the rs 4762 & 0.473 & 0.6 & -0.098 & 0.39 & -0.058 & 0.08 \\
\hline \multicolumn{7}{|c|}{ All models were adjusted for age, sex, smoking, and the values of dependent variables at the enrollment in the study. } \\
\hline
\end{tabular}

Table 5: Multivariate linear regression analysis for association of polymorphisms rs699 and rs4762 of the AGT gene with subclinical markers of carotid atherosclerosis progression in subjects with T2DM.

\section{Discussion}

In the study we confirmed an association between the AA genotype of the rs699 polymorphism of the AGT gene with the more rapid progression of carotid plaque thickness, whereas it was not associated with other markers of atherosclerosis progression. Contrary, polymorphism rs4762 of the AGT gene did not have a major impact on markers of carotid atherosclerosis progression in our population.

We speculate that the effect of the rs699 might be mediated via its effect on AGT serum levels, since the rs699 was found to correlate with plasma AGT concentrations [14]. There have been very few studies investigating the association between the AGT gene polymorphisms and markers of carotid atherosclerosis in either general population or in subjects with T2DM $[8,9,17-20]$. To our knowledge only one such study was performed in subjects with T2DM (European Americans and African Americans in the Diabetes Heart Study), and the rs699 did not appear to strongly influence subclinical cardiovascular disease (CIMT) in this population (20). This report is in accordance with our findings, since we also could not find significant impact of tested polymorphisms (rs699, rs4762) on CIMT at baseline. Moreover, Arnett et al. [9] reported no evidence that the rs699 of the AGT gene was associated with carotid intima-media thickness in middle-aged adults with no history of cardiovascular disease [7]. Similarly, Barley et al. [17] failed to demonstrate an association between the rs699 of the 
Citation: Merlo S, Starcevic JN, Mankoc S, Letonja MS, Vujkovac AC, et al. (2016) Polymorphisms rs699 and rs4762 of the Angiotensinogen Gene and Progression of Carotid Atherosclerosis in Patients with Type 2 Diabetes Mellitus. J Diabetic Complications Med 1: 107. doi: $10.4172 / \mathrm{jdcm} .1000107$

Page 5 of 5

AGT gene and either CIMT or cerebrovascular disease in one hundred consecutive Caucasian patients with internal carotid artery territory ischemia (TIA or stroke) [17]. Moreover, Sticchi et al also failed to report an association between carotid stenosis and the rs699 of the AGT gene [11]. Similarly, Losito et al. [12] failed to demonstrate an association between AGT gene polymorphisms (rs699, rs4762 $\mathrm{T} 174 \mathrm{M})$ and either cerebrovascular disease or carotid stenosis in dialysis patients [10]. Contrary to several studies performed in either Caucasians or African Americans, Tabara et al. [11] reported an association between the rs699 of the AGT gene and CIMT in a middleaged Japanese population [9].

Annual CIMT progression rate and the increase in total plaque thickness correlated differently with genetic and non-genetic risk factors for atherosclerosis development and progression, thus further supporting the hypothesis that CIMT and plaques are biologically distinct entities with different genetic backgrounds.

\section{Conclusions}

In conclusion, the rs699 of the AGT gene is a potential genetic marker of carotid atherosclerosis progression (expressed as increase in carotid plaque thickness) in Slovenian middle-aged patients (Caucasians) with T2DM. The rs699 of the AGT gene did not affect other ultrasonographic markers of carotid atherosclerosis progression

\section{Acknowledgments}

The authors thank Mrs. Visam Bajt, BA, for revising the English.

\section{References}

1. Moreno PR, Fuster V (2004) New aspects in the pathogenesis of diabetic atherothrombosis. J Am Coll Cardiol 44: 2293-2300.

2. Grundy SM, Benjamin IJ, Burke GL, Chait A, Eckel RH, et al. (1999) Diabetes and cardiovascular disease: a statement for healthcare professionals from the American Heart Association. Circulation 100: 1134-1146.

3. Spence JD, Hegele RA (2004) Noninvasive phenotypes of atherosclerosis: similar windows but different views. Stroke 35: 649-653.

4. Mookadam F, Moustafa SE, Lester SJ, Warsame T (2010) Subclinical atherosclerosis: evolving role of carotid intima-media thickness. Prev Cardiol 13: 186-197.

5. O'Leary DH, Polak JF, Kronmal RA, Manolio TA, Burke GL, et al. (1999) Carotid-artery intima and media thickness as a risk factor for myocardial infarction and stroke in older adults. Cardiovascular Health Study Collaborative Research Group. N Engl J Med 340: 14-22.

6. Polak JF, Szklo M, Kronmal RA, Burke GL, Shea S, et al. (2013) The value of carotid artery plaque and intima-media thickness for incident cardiovascular disease: the multi-ethnic study of atherosclerosis. J Am Heart Assoc 2: e000087.

7. Cambien F, Poirier O, Lecerf L, Evans A, Cambou JP, et al. (1992) Deletion polymorphism in the gene for angiotensin-converting enzyme is a potent risk factor for myocardial infarction. Nature 359: 641-644.

8. Katsuya T, Koike G, Yee TW, Sharpe N, Jackson R, et al. (1995) Association of angiotensinogen gene T235 variant with increased risk of coronary heart disease. Lancet 345: 1600-1603.

9. Arnett DK, Borecki IB, Ludwig EH, Pankow JS, Myers R, et al. (1998) Angiotensinogen and angiotensin converting enzyme genotypes and carotid atherosclerosis: the atherosclerosis risk in communities and the NHLBI family heart studies. Atherosclerosis 138: 111-116.
10. Islam MS, Lehtimaki T, Juonala M, Kahonen M, Hutri-Kahonen N,et al. (2006) Polymorphism of the angiotensin-converting enzyme (ACE) and angiotesinogen (AGT) genes and their associations with blood pressure and carotid artery intima media thickness among healthy Finnish young adults--the Cardiovascular Risk in Young Finns Study. Atherosclerosis 188: 316-322.

11. Tabara Y, Kohara K, Nakura J, Miki T (2001) Risk factor-gene interaction in carotid atherosclerosis: effect of gene polymorphisms of reninangiotensin system. J Hum Genet 46: 278-284.

12. Losito A, Kalidas K, Santoni S, Ceccarelli L, Jeffery S (2002) Polymorphism of renin-angiotensin system genes in dialysis patients-association with cerebrovascular disease. Nephrol Dial Transplant 17: 2184-2188.

13. Sticchi E, Romagnuolo I, Sofi F, Pratesi G, Pulli R, et al. (2011) Association between polymorphisms of the renin angiotensin system and carotid stenosis. J Vasc Surg 54: 467-473.

14. Jeunemaitre X, Lifton RP, Hunt SC, Williams RR, Lalouel JM (1992) Absence of linkage between the angiotensin converting enzyme locus and human essential hypertension. Nat Genet 1: 72-75.

15. Jeunemaitre X, Soubrier F, Kotelevtsev YV, Lifton RP, Williams CS, et al. (1992) Molecular basis of human hypertension: role of angiotensinogen. Cell 71: 169-180.

16. Bloem LJ, Foroud TM, Ambrosius WT, Hanna MP, Tewksbury DA, et al. (1997) Association of the angiotensinogen gene to serum angiotensinogen in blacks and whites. Hypertension 29: 1078-1082.

17. Barley J, Markus H, Brown M, Carter N (1995) Lack of association between angiotensinogen polymorphism (M235T) and cerebrovascular disease and carotid atheroma. J Hum Hypertens 9: 681-683.

18. Dessi-Fulgheri P, Catalini R, Sarzani R, Sturbini S, Siragusa N, et al. (1995) Angiotensin converting enzyme gene polymorphism and carotid atherosclerosis in a low-risk population. J Hypertens 13: 1593-1596.

19. Hung J, McQuillan BM, Nidorf M, Thompson PL, Beilby JP (1999) Angiotensin-converting enzyme gene polymorphism and carotid wall thickening in a community population. Arterioscler Thromb Vasc Biol 19: 1969-1974.

20. Burdon KP, Langefeld CD, Wagenknecht LE, Carr JJ, Freedman BI, et al. (2006) Association analysis of genes in the renin-angiotensin system with subclinical cardiovascular disease in families with Type 2 diabetes mellitus: the Diabetes Heart Study. Diabet Med 23: 228-234.

21. Touboul PJ, Hennerici MG, Meairs S, Adams H, Amarenco P, et al. (2007) Mannheim carotidintima-media thickness consensus (2004-2006). An update on behalf of the Advisory Board of the 3rd and 4th Watching the Risk Symposium, 13th and 15th European Stroke Conferences, Mannheim,Germany, 2004, and Brussels, Belgium, 2006. Cerebrovasc Dis 23: 75-80.

22. Nikolajevic Starcevic J, Santl Letonja M, Praznikar ZJ, Makuc J, Vujkovac AC, et al. (2014) Polymorphisms XbaI (rs693) and EcoRI (rs1042031) of the ApoB gene are associated with carotid plaques but not with carotid intima-media thickness in patients with diabetes mellitus type 2. Vasa 43: 171-180.

23. Geroulakos G, Ramaswami G, Nicolaides A, James K, Labropoulos N, et al. (1993) Characterization of symptomatic and asymptomatic carotid plaques using high-resolution real-time ultrasonography. Br J Surg 80: 1274-1277.

24. Manolio TA, Boerwinkle E, O'Donnell CJ, Wilson AF (2004) Genetics of ultrasonographic carotid atherosclerosis. Arterioscler Thromb Vasc Biol 24: 1567-1577. 